\title{
Who Is Rational?
}

\section{Studies of Individual Differences in Reasoning Keith E. Stanovich}

Mahwah, NJ: Lawrence Erlbaum Associates, 1999. Pp. xvi, 1-296.

Hardcover: ISBN 0-8058-2472-3, U.S. \$69.95. Paper: ISBN 0-80582473-1, U.S. $\$ 32.50$.

\section{Reviewed by David Hitchcock}

This is an important book.

It addresses the question: Are human beings systematically irrational? They would be so if they were "hard-wired" to reason badly on certain types of tasks. Even if they could discover on reflection that the reasoning was bad, the unreflective tendency to reason badly would be a systematic irrationality.

According to Stanovich, psychologists have shown that "people assess probabilities incorrectly, they display confirmation bias, they test hypotheses inefficiently, they violate the axioms of utility theory, they do not properly calibrate degrees of belief, they overproject their own opinions onto others, they allow prior knowledge to become implicated in deductive reasoning, they systematically underweight information about nonoccurrence when evaluating covariation, and they display numerous other information-processing biases." (1-2) Such cognitive psychologists as Nisbett and Ross (1980) and Kahneman, Slovic and Tversky (1982) interpret this apparently dismal typical performance as evidence of hard-wired "heuristics and biases" (whose presence can be given an evolutionary explanation) which are sometimes irrational. Critics have proposed four alternative explanations.

(1) Are the deficiencies just unsystematic performance errors of basically competent subjects due to such temporary psychological malfunctions as inattention or memory lapses? Stanovich and West (1998a) administered to the same subjects four types of reasoning tests: syllogistic reasoning, selection, statistical reasoning, argument evaluation. They assumed that, if mistakes were random performance errors, there would no significant correlation between scores on the different types of tests. In fact, they found modest but statistically very significant correlations (at the .001 level) between all pairs of scores except those on statistical reasoning and argument evaluation. Hence, they concluded, not all mistakes on such reasoning tasks are random performance errors. 
(2) Are the deficiencies only apparent, because interpreters of the results have used the wrong normative model? This suggestion tends to rest on philosophical arguments from charity (Dennett 1987) or reflective equilibrium (Cohen 1981) that human beings are necessarily rational-a view Stanovich calls Panglossian. Stanovich convincingly discredits (17-27) these a priori arguments; in particular, he argues that any reflective equilibrium used to justify a normative model of reasoning should be wide (incorporating appeal to other relevant principles) and restricted to those whose judgment counts (experts and good reasoners). To empirically evaluate Panglossian defences of alternative normative models, Stanovich used the understanding/acceptance principle of Slovic and Tversky (1974): the deeper the understanding of a correct normative model, the greater the readiness to accept it. On this principle, people presented with arguments for two competing normative models will tend to change their performance towards the correct one. Further, people with cognitive and personality characteristics more conducive to deeper understanding (higher SAT scores, higher need for cognition) will be more likely to favour a correct normative model; thus, the highly significant correlations between SAT Total scores and performance on the eight reasoning tasks mentioned above support the standard model. For two other reasoning tasks (ignoring noncausal base rates and projecting one's own opinion onto the general population), results undermined the standard model; projecting one's own opinion onto the general population turned out to be a rational strategy, and better reasoners were more likely to ignore noncausal base rates in computing probabilities (e.g. the probability that a person with a positive test result has actually been infected with HIV), for reasons Stanovich does not satisfactorily explain.

(3) Do the tasks given exceed the computational capacity of the human brain? This explanation comes from "Apologists" like Gigerenzer (1991), who recognize systematic human deviations from normative rationality but attribute them to computational and other resource limitations, which dictate a prescriptive model different from the standard normative model; Gigerenzer (1991) and others argue on evolutionary grounds that the brain must have evolved to reason correctly within its computational limitations. Among A pologists, "cognitive ecologists" recommend attention to presenting information in a form which humans can readily process, and are skeptical about the possibility of improving human rational performance. To test the Apologists' hypothesis of computational limitations, Stanovich and West (1998b) administered the Scholastic Aptitude Test (SAT) and other tests of cognitive capacity "known to load highly on psychometric g" (39), a hypothesized "general intelligence" factor. Subjects with higher SAT Total scores did significantly better on each of eight types of reasoning tasks (syllogisms, selection, statistical reasoning, argument evaluation, covariation detection, hypothesis-testing bias, outcome bias, if/only thinking); the correlation between a composite score on seven of 
the reasoning tasks (excluding selection) and the SAT Total score was a very substantial .547 (based on 527 subjects, all university students). This correlation was apparently not due to differential backgrounds in mathematics and statistics; subjects who did well on a given task did not differ significantly in their mathematics background from subjects who did poorly. Thus, some reasoning deficiencies can be explained by deficiencies in "brain power," especially on the selection task. But not all. Some subjects with the lowest scores on cognitive aptitude gave the "correct" answers on the various reasoning tasks..

4) Have experimental subjects interpreted the task differently? Here the problem is to determine not only whether subjects who give a "wrong" answer have interpreted the question differently than intended, but also whether they were rational to do so. Stanovich again applies the understanding/acceptance principle: the rational task construal should be the one which subjects with greater cognitive ability or more reflective personality will disproportionately prefer, and the one to which subjects should disproportionately move after being exposed to arguments for two alternative construals of a task. On four tasks where experts disagree about which construal is rational, he looked for differences in cognitive ability and in performance on other reasoning tasks between subjects answering according to one construal and those answering according to the other; on three of these tasks (a framing problem, a conjunction problem, a nondeontic selection task) he found a significant difference favouring the standard task construal, and on the fourth one (estimating subjective probability) no significant difference in either direction.

Thus, Stanovich concludes, the four hypotheses of unsystematic performance errors, wrong normative model, computational limitations and alternative task construal explain some but not all the apparent deficiencies in human rational performance. If we look only at reasoning tasks where empirical results support the standard normative model and standard task construal, and we factor out the influence of computational power, we still find systematic correlations between performance on the various reasoning tasks. These remaining systematic deficiencies, Stanovich speculates, reflect a fundamental computational bias of human cognition: contextualization. Human beings have two different systems of reasoning. Interactional intelligence, evolved for its ability to quickly discern other people's intentions in conversational and other interactions, is an unconscious, inflexible, automatic system driven by considerations of relevance. Analytic intelligence is a conscious, flexible, controllable system which is decontextualized. Our interactive intelligence contextualizes information in various ways: it applies Gricean conversational principles, contextualizes problems, sees design and pattern in situations, reasons enthymematically from unstated assumptions, and thinks narratively. Mostly this contextualization helps our thinking, and we should use it when it does. Sometimes however it is inappropriate; a more formal, decontextualized 
approach is required, and our analytic intelligence must override our interactional intelligence. In such conflict situations, the associational heuristics of interactional intelligence will immediately prompt one response, and analytic intelligence will prompt another after some reflection. People need to learn how and when to use analytic intelligence to override interactional intelligence; our technologically organized society makes it more and more necessary that they do so.

What types of people succeed in overriding interactional intelligence in conflict situations? As one might expect, subjects with greater cognitive ability (as measured by SAT Total scores) were more likely to do so. But so were those with the dispositions characteristic of an ideal critical thinker: even after controlling for differences in cognitive ability, reasoning performance correlated with degree of open-mindedness and epistemic flexibility (cultivating reflectiveness rather than impulsivity, seeking and processing information that disconfirms one's belief, being willing to change one's beliefs in the face of contradictory evidence). Further, these dispositions tended to cut across different domains.

In contrast to the Panglossians and Apologists, Stanovich is a "Meliorist:" there is systematic human irrationality, part of it is due to factors other than resource limitations, and this part is to some extent remediable. To increase rationality, he thinks, it is at least as important to cultivate domain-general critical thinking dispositions as to learn algorithms. Stanovich does not consider a fourth possible position, Pessimism: human beings have systematic irrationalities which are not correctable.

Stanovich's results seem to refute the Panglossians and to show that Apologists are partly correct-"their emphasis on cognitive alteration provides a muchneeded counterpoint to the Meliorist emphasis on cognitive change" (233)but only partly. His identification of successful reasoners in conflict situations shows that not all human beings are hopelessly irrational. But it does not show that the remaining ones can be educated to be less irrational. To provide empirical support to that aspect of the Meliorist position, one would have to investigate the effect of training on performance on reasoning tasks; for some efforts in this direction with cautiously optimistic results, see Nisbett (1993)..

Empirical research in cognitive psychology has tended to focus on the explanation of typical deficient responses on reasoning tasks. Stanovich on the other hand investigates individual differences: Why do some individuals perform well and others badly? This is a fruitful research programme, whose future development holds much promise of helping us to understand how and why some humans are irrational in certain situations, what distinguishes those who are from those who are not, and how if at all such irrationality can be reduced. 


\section{References}

Cohen, L. J. 1981. "Can human irrationality be experimentally demonstrated?" Behavioral and Brain Sciences 4, 317-370.

Dennett, D. C. 1987. The Intentional Stance. Cambridge, MA: MIT Press.

Gigerenzer, G. 1991. "How to make cognitive illusions disappear: Beyond "heuristics and biases," European Review of Social Psychology, 2, 83-115.

Kahneman, D., P. Slovic and A. Tversky. 1982. Judgment under Uncertainty: Heuristics and Biases. Cambridge: Cambridge University Press.

Nisbett, R. E. 1993. Rules for Reasoning. Hillsdale, NJ: Lawrence Erlbaum Associates.

Nisbett, R. E., and L. Ross. 1980. Human Inference: Strategies and Shortcomings of Social Judgment. Englewood Cliffs, NJ: Prentice-Hall.

Slovic, P., and A. Tversky. 1974. "Who accepts Savage's axiom?" Behavioral Science, 19, 368-373.

Stanovich, K. E., and R. F. West. 1998a. "Individual differences in rational thought," Journal of Experimental Psychology: General, 127, 161-188.

Stanovich, K. E., and R. F. West. 1998b. "Who uses base rates and $\mathrm{P}(\mathrm{D} / \sim \mathrm{H})$ ? An analysis of individual differences," Memory \& Cognition, 28, 161-179.

David Hitchcock Department of Philosophy

McMaster University

Hamilton, Ontario

Canada $28 \mathrm{~S} 4 \mathrm{Kl}$

hitchckd@mcmaster $c a$ 